\title{
Conflict-Related Population Health Research in Syria, 2011-2019: An Assessment of Information Gaps, Research Needs and Challenges, for The Lancet - AUB Commission on Syria
}

\section{Marian Abouzeid}

American University of Beirut; Deakin University

Manal Elzalabany

American University of Beirut

Iman Nuwayhid

American University of Beirut

Samer Jabbour ( $\sim$ sj22@aub.edu.lb )

American University of Beirut Faculty of Health Sciences https://orcid.org/0000-0002-7150-6856

Research

Keywords: Syria, Health research, Population, The Lancet, AUB Commission

Posted Date: October 19th, 2020

DOI: https://doi.org/10.21203/rs.3.rs-93301/v1

License: (c) (1) This work is licensed under a Creative Commons Attribution 4.0 International License.

Read Full License 


\section{Abstract}

Backgorund. While there has been a growth of research on health and the Syrian conflict, most such research covers Syrian refugees. There is limited information about the scope and focus of research on health and population inside Syria. While there are several systemtic and scoping literarure reviews of health of Syrian refugees, there has not been a sccoping review of research literature on health issues inside Syria.

Methods. As part of a broader scoping review covering January 2011 to December 2019, we examined English-language conflict-related research papers that studied health issues inside Syria and focused on Syrians or those permanently resident in Syria. We classified research articles based on the major thematic areas studied. We abstracted bibliometric information, study characteristics, funding statements and reported key limitations and challenges of conducting research. To gain additional insights or data, we examined separately publications reporting field and operational activities as well as personal reflections and narrative accounts of first-hand experiences inside Syria.

Results. Of 2,088 papers identified in the scoping review, 708 (34\%) exclusively focus on health issues of Syrians inside Syria, of which 350 (49\%) are conflict-related with. Of conflict-related publications, 89 $(25 \%)$ are research papers. Annual volume of research increased over time, from one publication in 2013 to 27 publications in each of 2018 and 2019. Damascus is the most frequently studied governorate $(n=33)$, followed by Aleppo $(n=25)$. Papers used a wide range of research methodologies, primarily quantitative $(n=68)$. The country of institutional affiliation(s) of first and last authors are Syria $(n=30,20$ respectively), the United States ( $n=25,19$ respectively) or the United Kingdom ( $n=12,10$ respectively). Themes most covered were health status, health system and humanitarian assistance, response or needs $(n=38,32,26$ respectively). Thirty one publications presented field and operational activities and eight publications were reflections or first-hand personal accounts of experiences inside Syria. Authors encountered contextual, methodological and administrative challenges in doing research on health inside Syria.

Conclusions. Although it is commonly stated that Syria is among the most documented of recent wars, our analysis shows that a relatively limited number of research studies focused on health or populations inside Syria have been published over the nine years of the conflict. Beyond the need to increase the volume of research, it is important to address the knowledge gaps identified in this review.

\section{Introduction}

It is commonly said that the armed conflict in Syria is among the most extensively studied and documented contemporary conflicts (Sigal 2016). There is an expanding volume of literature on a diverse range of health issues relating to the conflict, from attacks on healthcare and use of chemical weapons to refugee health status assessment. Research in and on active conflict zones is inherently difficult, and these challenges are reflected in the focus, nature and volume of research outputs produced while an 
armed conflict is ongoing. For example, while the challenges facing the health systems of countries hosting large numbers of Syrian refugees have been examined (El-Khatib, Scales et al. 2013, Mipatrini, Stefanelli et al. 2017), research assessments of the fragmented health system(s) inside war-torn Syria are limited. Similarly, compared with populations inside Syria, Syrian refugee populations are more accessible and therefore have received comparatively more research attention, including reviews and syntheses of this large volume of published research (El Arnaout, Rutherford et al. 2019). To the best of our knowledge, to date a review of conflict-related research on health inside Syria has not been conducted. Such a review is essential to understand what thematic issues, population subgroups and geographic areas have been examined, identify knowledge gaps, and inform the health research agenda.

In this paper, we aim to characterise conflict-related research published on health issues and populations inside Syria over the course of the conflict, in order to a) understand who is researching what, where, when and how; $b$ ) identify knowledge gaps and needs, including understudied population groups and geographic areas or issues that warrant further attention; and c) better understand the specific challenges encountered by those who have published research on war-torn Syria, in order to consider strategies to mitigate the impacts of such challenges on future research.

\section{Methods}

\section{Search strategy}

This study is part of a broader scoping review of the health peer-reviewed literature published in Arabic, English, or French over the period spanning January 2011 to December 2019. Full methodological details are available elsewhere (Elzalabany et al, in progress). Briefly, we conducted a comprehensive scoping search of literature indexed in seven health databases (PubMed, Medline (OVID), CINAHL Complete, Global Health, EMBASE, Web of Science, Scopus), which identified a total of 2088 peer-reviewed papers focusing on human health and Syria or Syrians published during the specified period. For this analysis, we examined only English-language conflict-related research papers that studied health issues inside Syria and focused on Syrians or those permanently resident in Syria (e.g. Palestinian or Iraqi refugees in Syria). We defined research papers as publications of any type (including traditional research papers, letters, commentaries and other) whose major focus is to report studies that involve the primary collection of data, or the secondary analysis and interpretation of existing data. Therefore, review publications and other literature evidence syntheses are not included in this research review. We also excluded clinical case studies and case series, conflict-related papers focused only on Syrians outside Syria (e.g. studies of Syrian refugees), and studies conducted in multiple settings where Syria was one of many countries examined (including studies examining populations both inside Syria and refugees). Field and operational activities publications, defined as papers describing operational activities or organizational field experiences inside Syria but not presenting research per se (e.g. papers describing set-up of a field facility and number of patients seen, or describing humanitarian operations), which provide important insights or data about health inside Syria during the conflict, were considered separately to the research papers. Similarly, personal reflections and narrative accounts of first-hand 
experiences inside Syria were considered separately. News reports and news interviews with personnel inside Syria were not included in this review.

\section{Literature dataset analysis}

We classified research articles into six categories based on the major thematic areas studied: mortality; population health status; health determinants and risks (including behavioural, physiological, environmental and social determinants of health); humanitarian assistance, response or needs (including any studies conducted by humanitarian agencies or analysis of services provided by humanitarian actors); healthcare system (including papers examining any of the six health system pillars as defined by the World Health Organization (World Health Organization 2007), namely service delivery (unless delivered by humanitarian actors), health workforce, health information systems, pharmaceuticals and essential medicines, financing, governance); and war strategies \& alleged international humanitarian law $(\mathrm{HL})$ violations (including studies reporting on warfare, besiegement, and related human rights violations, attacks on civilian infrastructures such as health facilities, and publications on chemical attacks). A single paper could be classified into multiple thematic categories if it had a major focus on more than one theme.

For each paper, we abstracted bibliometric information and study characteristics (including country of affiliation(s) of first and last authors, aims, study period, methodology, governorates/ geographic location of the study, study population). We also extracted qualitative data on key limitations and challenges of conducting research as described by the authors, and categorized these as contextual, methodological or administrative. Where available, funding statements were also reviewed and assigned to one of three categories (funded, not funded, not reported). Classification of each paper was discussed by three reviewers.

We used basic descriptive statistics to summarise key bibliometric characteristics of the research papers and changes in the volume and focus of research over time. Key challenges encountered were summarized narratively.

\section{Results}

Of 2,088 papers identified in the scoping review, 708 (34\%) exclusively focus on health issues of Syrians inside Syria, of which 350 (49\%) are conflict-related. Of these 350 conflict-related publications, 89 (25\%) are research papers and form the material of this analysis. We also identified 31 field and operational activities papers focused on health inside Syria and eight personal narrative reflections, which we examine separately.

Table 1 presents summary characteristics of the 89 conflict-related research papers. The conflict in Syria started in 2011 but there were no research papers published during 2011-2012. Thereafter the annual volume of research increased over time, from one publication in 2013, three in 2014, to 27 publications in 
each of 2018 and 2019. There is considerable variation in the governorates studied by thematic focus and over time (Table 1, Fig. 1). Damascus is the most frequently studied governorate $(n=33)$, followed by Aleppo $(n=25)$, Idlib $(n=20)$, Lattakia $(n=15)$ and Hama $(n=14)$. Deir Al Zour $(n=3)$, Quenietra $(n=3)$ and Al-Sweida $(n=3)$ are the least frequently studied. Thirteen papers have a national scope. Several papers do not identify specific governorates, instead referring to the controlling factions, describing for example opposition-controlled territories generally. There are no papers on health in areas while controlled by the so-called Islamic State (IS).

Papers have used a wide range of research methodologies, including primary quantitative methods ( $\mathrm{n}=$ 40) such as surveys, questionnaires and clinical trials; secondary quantitative data analysis $(n=28)$ mainly using surveillance system, medical record or program data, and qualitative methodologies $(\mathrm{n}=$ 15). Six papers used mixed methods (Table 1).

For the majority of papers, the country of institutional affiliation(s) of first and last (assumed to be the senior) authors are Syria $(n=30,20$ respectively), the United States $(n=25,19$ respectively) or the United Kingdom ( $n=12,10$ respectively). For 19 papers $(21 \%)$, both first and last authors had a Syrian affiliation. Of the 37 papers reporting a specific funding source, five listed Syrian universities as the funding source.

\section{Research themes}

Table 2 presents detailed summaries of each research paper.

Health status is the most frequently researched theme, examined in 38 research papers covering nutrition (Hoetjes, Rhymer et al. 2014, Vernier, Cramond et al. 2019), communicable diseases and/or vaccination status (Alasaad 2013, Tajaldin, Almilaji et al. 2015, Ismail, Abbara et al. 2016, Sparrow, Almilaji et al. 2016, Alsaied, Mawas et al. 2017, Baaity, Almahmoud et al. 2017, Hawat, Husein et al. 2017, van Berlaer, Elsafti et al. 2017, de Lima Pereira, Southgate et al. 2018, Khamis and Ghaddar 2018, Rehman, Walochnik et al. 2018, Muhjazi, Gabrielli et al. 2019, Vernier, Cramond et al. 2019, Youssef, Harfouch et al. 2019), mental health (Charlson, Lee et al. 2016, Al-Saadi, Addeen et al. 2017, Mohammad, Rafea et al. 2017, Hamid and Dashash 2018, Kubitary and Alsaleh 2018, Kubitary and Alsaleh 2018, Perkins, Ajeeb et al. 2018, Falb, Blackwell et al. 2019, Roumieh, Bashour et al. 2019, Vernier, Cramond et al. 2019), child (Elsafti, van Berlaer et al. 2016, van Berlaer, Elsafti et al. 2017, Meiqari, Hoetjes et al. 2018, Terkawi, Bakri et al. 2019) and maternal (Terkawi, Bakri et al. 2019) health, oral health (Ballouk and Dashash 2018, Hamid and Dashash 2018, Alhaffar, Alawabdi et al. 2019, Ballouk and Dashash 2019), gender-based violence (Blackwell, Casey et al. 2019), anaemia (Albaroudi, Khodder et al. 2018) and non-communicable diseases (Mohammad, Rafea et al. 2017, Hamzeh, Almhanni et al. 2019, Vernier, Cramond et al. 2019). Of studies examining injuries, three are studies of hospital patients (Arafat, Alsabek et al. 2017, Darwish, Mahfouz et al. 2018, Okeeffe, Vernier et al. 2019), one examines injury burden among children surveyed at home and in internally displaced population (IDP) camps (van Berlaer, Elsafti et al. 2017) and one reports injury counts among children and the general population as provided by key informants(Diggle, Welsch et al. 2017). One additional study reports reasons for patient encounters at health facilities (Alsaied, Mawas et al. 2017). 
Of these health status studies, a few also report on socioeconomic associations with disease burden (Albaroudi, Khodder et al. 2018, Alhaffar, Alawabdi et al. 2019, Falb, Blackwell et al. 2019, Roumieh, Bashour et al. 2019), health seeking behaviours (Hamzeh, Almhanni et al. 2019, Terkawi, Bakri et al. 2019) and exposure to violence as a determinant of health (Vernier, Cramond et al. 2019). Several other papers focus primarily on health determinants and risks, including neighbourhood socioeconomic status (Ahmad 2014, Ahmad, Fouad et al. 2018), occupational stress (Othman, Steel et al. 2018), food security (Doocy, Tappis et al. 2017), and smoking prevalence and smoking behaviours before and during the war (Idris, Al Saadi et al. 2018).

Thirty-two research papers examine the various pillars of the health system. Research on health workforce includes studies of the prevalence of psychological symptoms and burnout among medical students and trainees (Al-Saadi, Addeen et al. 2017, Alhaffar, Abbas et al. 2019), workforce training (Abbas, Sawaf et al. 2018), interventions using social media platforms and remote learning as a teaching medium (Alshiekhly, Arrar et al. 2015), consideration of the impact of conflict on workforce size, support or wellbeing (Sekkarie, Zanabli et al. 2015, Mowafi, Hariri et al. 2016, Sahloul, Salem et al. 2017, Footer, Clouse et al. 2018, Fardousi, Douedari et al. 2019, Jamal, Alameddine et al. 2019), including numbers of health workers killed or injured by attacks on health care (Elamein, Bower et al. 2017, Fouad, Sparrow et al. 2017), workforce wellbeing interventions (Othman, Steel et al. 2018), workforce requirements to address estimates of likely disease burden (Charlson, Lee et al. 2016), and studies of medical student career plans (Sawaf, Abbas et al. 2018) and attitudes to research (Turk, Al Saadi et al. 2018).

Health information systems are studied largely in the context of communicable disease surveillance, and comparison of surveillance systems covering government and non-government controlled areas (Tajaldin, Almilaji et al. 2015, Ismail, Abbara et al. 2016, Sparrow, Almilaji et al. 2016). Two papers cover issues of health system governance, one through key informant interviews with health service providers, donors and end-users in opposition-controlled areas (Douedari and Howard 2019) and the other through interviews with UNRWA personnel that included consideration of adaptive mechanisms used to ensure resilience and ongoing function of the UNRWA health system (Jamal, Alameddine et al. 2019). Essential medicines are the focus of two papers, one of which surveyed community pharmacists in Damascus and Damascus countryside regarding prescription drug misuse and characteristics of patients seeking such medications (Alaryan, Hasan et al. 2019), and the other considered impacts of conflict on the UNRWA system, including on availability of medicines and medical supplies (Jamal, Alameddine et al. 2019). There are no studies on health financing.

Twenty-one papers cover Issues of service provision including renal (Sekkarie, Zanabli et al. 2015), mental health (Charlson, Lee et al. 2016, Jefee-Bahloul, Duchen et al. 2016), orthopaedic (Alhammoud, Maaz et al. 2019), cancer (Sahloul, Salem et al. 2017), communicable disease surveillance (Khamis and Ghaddar 2018), respiratory (Mohammad, Shaaban et al. 2019) antenatal (Terkawi, Bakri et al. 2019), mental health (Kubitary and Alsaleh 2018) and trauma services (Mowafi, Hariri et al. 2016, Alothman, Tamer et al. 2019, Okeeffe, Vernier et al. 2019), disruptions to service provision due to attacks on healthcare (Elamein, Bower et al. 2017, Fouad, Sparrow et al. 2017, Footer, Clouse et al. 2018, Haar, Risko 
et al. 2018, Wong and Chen 2018), challenges of service provision under siege (Morrison 2018, Fardousi, Douedari et al. 2019), factors enabling sustained UNRWA service delivery (Jamal, Alameddine et al. 2019), and interplays of local service provision with cross-border humanitarian assistance (Duclos, Ekzayez et al. 2019).

Humanitarian assistance, response or needs (which included any studies conducted or analysis of services provided by humanitarian agencies) are the focus of 26 papers. These include estimates of IDP size and trends (Doocy, Lyles et al. 2015), humanitarian needs assessments among the general population, many of whom were displaced, in nine predominantly government-controlled governorates in 2014 (Doocy, Delbiso et al. 2015, Doocy, Lyles et al. 2015) and among the general population (Doocy and Lyles 2018) and displaced and female-headed households in 10 largely urban government-controlled areas in 2016 (Doocy and Lyles 2017); identifying optimal shelter (Hallak, Koyuncu et al. 2019) and primary healthcare (Mic, Koyuncu et al. 2019) locations for IDPs in Idlib based on beneficiary needs assessments and modelling, and a snapshot survey of community income and humanitarian assistance in Idlib (Cummins and Moharram 2017). Other studies included analysis of Qatar Red Crescent surveys of the impacts of the conflict on education, family and public health status (Elsafti, van Berlaer et al. 2016) and diagnoses, injuries and comorbidities (van Berlaer, Elsafti et al. 2017) among children in Northern Syria in 2015; and household surveys of water, sanitation and hygiene (WASH) and health outcomes in opposition-controlled Daraa and Quneitra in 2016-17 (Sikder, Daraz et al. 2018). Review of humanitarian programmatic data and operations included middle-upper arm circumference screening, survey of living conditions and food security, and nutritional programming administered by Medecins Sans Frontiers (MSF) in Al-Raqqa in 2013 (Hoetjes, Rhymer et al. 2014), MSF vaccine-preventable disease risk assessment, pre- and post-vaccine coverage surveys and immunization activity in Aleppo in 2015 (de Lima Pereira, Southgate et al. 2018), 2012-2014 surgical data from an MSF field hospital in Northwest Syria (Trelles, Dominguez et al. 2015), blast injuries managed at an MSF-supported facility in Raqqa in 2017-18 (Okeeffe, Vernier et al. 2019), MSF paediatric consultations in Aleppo and Raqqa in 2013-16 (Meiqari, Hoetjes et al. 2018), MSF assessment of health status of recently arrived IDPs in Al-Raqqa in 2017 (Vernier, Cramond et al. 2019), primary care services delivered by 10 Union of Medical Care and Relief Organisations (UOSSM) centres in opposition-controlled territories in 2014-2015 (Alsaied, Mawas et al. 2017), and analysis of data from the humanitarian health response in contested and oppositioncontrolled areas in 2013-14 (Diggle, Welsch et al. 2017). Additional interventions and program evaluations included delivery and evaluation of an intervention through provision of information and follow-up questionnaire in bread packages being distributed by a humanitarian organization in Northern Syria (El-Khani, Cartwright et al. 2016), evaluation of three modes of food assistance programming in Idlib in 2014-15 (Doocy, Tappis et al. 2017), evaluation of an International Rescue Committee cash assistance program on violence against women in Raqqa (Blackwell, Casey et al. 2019), evaluation of effectiveness of multi-level WASH risk reduction interventions in southern Syria in 2018 (Sikder, Daraz et al. 2018) and examination of the impact of a psychosocial support program on the wellbeing of a control and intervention group of farmers (Ziveri, Kiani et al. 2019). Several papers interviewed humanitarian workers, including humanitarian health staff working on non-communicable disease (NCD) care in Syria 
(Garry, Checchi et al. 2018) and those involved in the cross-border humanitarian health response from Turkey (Duclos, Ekzayez et al. 2019, Fradejas-Garcia 2019).

Fourteen papers research health issues related to war strategies and alleged IHL violations, including an expert panel review of YouTube videos following a sarin gas attack (Rosman, Eisenkraft et al. 2014) and interviews with healthcare workers in opposition-controlled areas regarding attacks on healthcare and challenges and experiences in responding to chemical attacks (Footer, Clouse et al. 2018). Other research in this theme examined attacks on health care (Elamein, Bower et al. 2017, Fouad, Sparrow et al. 2017, Haar, Risko et al. 2018, Wong and Chen 2018, Ri, Blair et al. 2019), areas under or the effects of siege (Sahloul, Salem et al. 2017, Morrison 2018, Fardousi, Douedari et al. 2019), and war-related mortality (Guha-Sapir, Rodriguez-Llanes et al. 2015, Chen, Shrivastava et al. 2018, Guha-Sapir, Schlüter et al. 2018, $\mathrm{Ri}$, Blair et al. 2019) including a study of characteristics of deceased victims of a chemical weapons attack (Rodriguez-Llanes, Guha-Sapir et al. 2018).

Mortality is the subject of ten papers, which report mortality counts provided by key informants in contested and opposition areas (Diggle, Welsch et al. 2017); examine mortality data documented by the Violations Documentation Centre (VDC) (Guha-Sapir, Rodriguez-Llanes et al. 2015, Guha-Sapir, Schlüter et al. 2018, Rodriguez-Llanes, Guha-Sapir et al. 2018)), examine associations between attacks on healthcare and civilian casualties (Ri, Blair et al. 2019) or confirm conflict events in a fake-news data set (Abu Salem, Al Feel et al. 2019); use capture-recapture methods on four data sets to estimate mortality in two governorates (Price, Gohdes et al. 2015); estimate the number of unique identifiable deaths by deduplicating four data sets (Chen, Shrivastava et al. 2018); use spatio-temporal death data to forecast conflict events (Fujita, Shinomoto et al. 2017) and report on a household survey of IDPs in Raqqa and retrospective one-year mortality, largely conflict-related deaths (Vernier, Cramond et al. 2019).

\section{Research themes by governorate}

Themes studied vary by governorate (Table 1, Fig. 1). In Damascus, health status is the most frequently studied theme $(n=14)$, followed by the healthcare system $(n=13)$. The healthcare system was also the main theme examined in studies of Aleppo $(n=12)$ and Idlib $(n=9)$. Humanitarian assistance, response or needs are most frequently studied in the north-west of Syria, including Aleppo $(n=7)$, Idlib $(n=6)$ and Lattakia $(n=6)$, and of the studies examining specific governorates, all 14 governorates were covered in at least one paper. Of the papers examining war strategies and alleged IHL violations, the majority include a focus on Aleppo $(n=6)$ or Damascus $(n=5)$. On the national level, the healthcare system is the most frequently studied theme $(n=7)$, followed by health status $(n=5)$, war strategies and alleged IHL violations $(n=4)$ and mortality $(n=3)$.

\section{Research themes by author country of affiliation}

Themes examined vary by country of affiliation of authors (Table 1). Authors with Syrian affiliations commonly publish on health status ( $n=21$ for first authors, $n=14$ for last authors), the healthcare system ( $n=11$ for first authors, $n=5$ for last authors), and health determinants and risks ( $n=4$ for first authors, $n$ 
= 3 for last authors), while the most frequently researched themes among US-affiliated authors are the healthcare system ( $n=11$ for first authors, $n=10$ for last authors), humanitarian assistance, response or needs ( $n=9$ for first authors, $n=5$ for last authors), health status ( $n=8$ for first authors, $n=3$ for last authors) and war strategies and alleged IHL violations ( $n=6$ for first authors, $n=8$ for last authors).

\section{Field and operational activities publications}

Table 3 presents a summary of the 31 papers presenting field and operational activities, of which 12 describe humanitarian assessment, responses or needs, including development of a rapid gender analysis tool (Quay 2019), cross-border, sectoral and cluster coordination mechanisms (Dolan 2014, Abdulahi 2017, Abdullah and Baker 2017, Madani 2017), and needs assessments and/or operational programming (Harrison, Dahman et al. 2013, Egendal and Badejo 2014, Khudari, Bozo et al. 2014, Kingori, Nasser et al. 2014, Littledike and Beck 2014, Reed 2014, Lester 2018). Nineteen papers discuss various aspects of the health system, most commonly reporting on experiences of establishing and / or presentations to field hospitals (Hasanin, Mukhtar et al. 2013, Sankari, Atassi et al. 2013, Alahdab, Omar et al. 2014, Attar 2014), or establishing or delivering specific services including renal (Al-Makki, Rifai et al. 2014, Saeed 2015), dental (Joury 2014), mental health (Jefee-Bahloul, Barkil-Oteo et al. 2016), obstetric (Hakeem and Jabri 2015) maternal and child health (Aburas, Najeeb et al. 2018), tele-cardiology (Alrifai, Alyousef et al. 2018), tele-intensive care (Moughrabieh and Weinert 2016, Ghbeis, Steffen et al. 2018), and tele-radiology (Mohammad, Mamoun et al. 2017, Masrani, Mamoun et al. 2018) care, and polio outbreak response activities (Mbaeyi, Wadood et al. 2018). Other papers described the national tuberculosis control program (Muhjazi, Baghdadi et al. 2018), activities of Syrian expatriate medical associations in supporting the healthcare system, incldung through training, establishment of hospitals and provision of telemedicine services (Hallam 2013), and translation and uptake of an online medical education platform into Arabic by Syrian medical students (Kouba, Amin et al. 2019). War strategies and alleged IHL violations are the secondary theme of two paper, one describing experiences in besieged settings (Masrani, Mamoun et al. 2018) and one paper reporting birth outcomes by chemical weapons exposure status for pregnant women seen at Al Ghouta hospital in late 2014. (Hakeem and Jabri 2015). Only $12(39 \%)$ of these field and operational activities publications are first-authored by an author with a Syrian affiliation. Of the 21 publications with multiple authors, only 4 (19\%) had a senior (last) author with a Syrian affiliation.

\section{Narrative personal reflections}

Eight publications were reflections or first-hand personal accounts of experiences inside Syria. These included reflections of an expatriate physician on his missions working in field hospitals (Attar 2016) including in Aleppo in 2013 (Attar 2014); experiences of a resident working in the neurosurgery department of a hospital under siege in Aleppo (Fakhouri 2017); experiences of a medical resident working in Aleppo University Hospital following a chemical weapons attack, including reports of number of patient presentations and outcomes (Kaadan and Cranmer 2018); experiences of medical volunteers during a mission in Idlib (Mahomed, Motara et al. 2016); and personal and professional experiences of a 
Syrian neurosurgeon working in Syria (Kassem 2016). Two papers are experiences of medical students in conflict-ravaged Syria, one publication reporting experiences in undertaking research and accessing research training (Saadi, Abbas et al. 2018) and another reporting experiences of studying medicine in conflict (Turk, Aboshady et al. 2016).

\section{Challenges reported in researching Syria}

Researchers discuss a range of considerations and challenges of conducting research in and on Syria (Table 4). Contextual challenges are largely related to safety and security issues, including the impact of conflict on access to both geographic areas (access often being limited to specific governorates or relatively safer areas) and study participants (including participant willingness to engage). Security considerations have impacted the ability to conduct research as planned.

Researchers report numerous methodological challenges, including limited data availability and access, data quality and completeness concerns, lack of population denominator data, and potential for bias at all stages of the research process.

Administrative considerations are largely related to securing permissions to conduct research and ethical review board processes, most notably the absence of such formal in-country governance structures. Conflict also impacted other aspects of research administration, including the availability of research funding.

\section{Discussion}

Although it is commonly stated that Syria is among the most documented of recent wars, our analysis shows that a relatively limited number of research studies focused on health or populations inside Syria have been published over the nine years of the conflict. There are several geographic and thematic information gaps which likely reflect a myriad of factors, including issues of access and other challenges of conducting research during active conflict. There is a relative paucity of research on several key pillars of the healthcare system such as governance, financing and essential medicines, and on a number of critical population health issues such as NCDs. Research coverage of governorates shows a heavy emphasis on Damascus and the north-west, with comparatively little research covering the north-east and the south of Syria. Our analysis does not identify any research on some specific vulnerable populations such as the current or formerly imprisoned/detainees, and very few studies of besieged areas.

Some thematic areas have received limited research attention.

Health status is the most frequently researched theme, with communicable diseases the most common focus. Given the disruption of health and social infrastructures during conflict, with attendant impacts on communicable disease surveillance and control, and the broad biosecurity and global health threat posed by outbreaks of communicable diseases such as polio, it is not surprising that communicable disease epidemiology and control is a major focus of research attention. Similarly, mental health is the focus of 
several papers which cover a number of population subgroups, including the health workforce (Al-Saadi, Addeen et al. 2017), women (Falb, Blackwell et al. 2019, Roumieh, Bashour et al. 2019), children (Hamid and Dashash 2018, Kubitary and Alsaleh 2018, Perkins, Ajeeb et al. 2018), selected patient populations (Kubitary and Alsaleh 2018), and IDPs (Mohammad, Rafea et al. 2017, Vernier, Cramond et al. 2019), in addition to modelling estimates of disease burden and associated workforce requirements for the general population (Charlson, Lee et al. 2016). This is a crucial area of research in a conflict context and in a cultural setting where mental health issues remain stigmatized.

Other direct health effects of conflict receive comparatively little research attention. For example, injury epidemiology is covered in just five papers, three of which described a cohort of inpatients with abdominal (Arafat, Alsabek et al. 2017), paediatric chest (Darwish, Mahfouz et al. 2018) or blast injuries (Okeeffe, Vernier et al. 2019). Understanding injury epidemiology is critical to informing health and social system needs, both to address immediate acute care needs but also to inform estimates of likely disability burden in future and requirements for health and social infrastructures and adaptive measures. This limited research focus may reflect data gaps, with lifesaving provision of care clearly a priority above record-keeping in acute emergencies and mass casualty events. The referral of many wounded individuals for treatment in neighboring countries may also partly explain this gap, supported by an observation from our broader scoping review that there is more injury research from Turkey, Israel and Jordan than there is from within Syria. Additionally, for injury epidemiology as well as other thematic areas, data access and data sharing arrangements may be an issue, with much service provision information, however (in)complete, held by humanitarian agencies and government bodies. Sharing of information with researchers for secondary data analysis is often a fraught process. This information divide and limited collaboration between researchers and operational organisations must be bridged, to minimize duplication of effort and ensure best outcomes for the populations who are the ultimate beneficiaries of all this work. Further, even when data are available to researchers, institutional processes, research governance mechanisms and data access arrangements may mean that data cannot actually be used and published in a timely manner.

NCDs represent another major research gap despite being identified as such in 2015 and a call for action issued (Coutts, Fouad et al. 2015). Prior to the onset of the conflict, Syria was in the midst of a demographic and epidemiological transition, with NCDs dominating disease burden and health expenditure (Taleb, Bahelah et al. 2015). Left unaddressed and due to disruptions to the health system, preventive measures and altered health behaviours, this underlying disease burden is likely to have magnified, and indeed studies among Syrian refugees indicate a high NCD burden (Rehr, Shoaib et al. 2018). It is likely that a similar high burden exists among populations inside Syria. This warrants urgent research attention.

For a protracted conflict that has caused a large number of deaths, surprisingly few research studies have examined mortality. Notably, most of the mortality research considers direct war-related deaths. Few studies report on general mortality or examine indirect conflict-related deaths, such as those due to treatment forgone and service unavailability, for instance cancer deaths due to lack of access to

Page $11 / 26$ 
chemotherapy or end-stage renal failure deaths due to lack of dialysis services (one paper provides an anecdotal estimate of renal deaths for one centre (Sekkarie, Zanabli et al. 2015)). Such information is essential at the facility, governorate and national levels, both to inform immediate needs and to drive accountability - the effects of war, and the impacts of atrocities such as killing a doctor or attacking a hospital, extend far beyond the immediate acute losses.

Accurately estimating mortality in conflict presents numerous challenges (Price, Gohdes et al. 2015) and several factors may explain the relative paucity of mortality research in Syria. Some data collections such as VDC are reliant on ground reporters, and relative inaccessibility of some geographic areas influences data collection and completeness. While multiple organizations are reportedly tracking conflict-related deaths, there is a gross disconnect between data collected by and available to humanitarian and human rights organizations and that available to researchers. National researchers based inside Syria may find it difficult to investigate this sensitive issue. Insecurities may render conducting household assessment on representative samples difficult, or generate security threats to families, witnesses or data collectors. In some instances, there may be no witnesses left to report the deaths (Price, Gohdes et al. 2015).

Disruption of health information infrastructure means limited availability and completeness of data from official local sources such as hospital records and vital registration data. The fact that the United Nations stopped officially reporting deaths in Syria since 2014 introduced a further barrier to rigorous analyses of deaths. Mortality data are also highly politicised. Recognising the data limitations and challenges, there is a clear need to advance methods for researching mortality in conflict, for example developing better estimates of mortality considering the difficulty in enumerating deaths (numerator) in a highly charged political environment and the changing population numbers (denominators) due to displacement.

War strategies and IHL violations are the focus of several papers, including those examining attacks on health care, effects of siege, and chemical weapons attacks. Attacks on health care in Syria have been well documented, both by the research community as well as by a number of human rights and humanitarian organisations. There are numerous methodological and contextual challenges to such research and in the studies included in this review, the validation of reported data on either chemical weapons or attacks on healthcare infrastructure and personnel is a commonly noted concern (Rosman, Eisenkraft et al. 2014, Elamein, Bower et al. 2017, Wong and Chen 2018), especially where the attacks are not associated with large numbers of fatalities or major physical property damage, which may lead to under-estimation of the number of events (Wong and Chen 2018) and under-reporting from ground sources. With standardized methodologies to monitor and report the attacks on healthcare lacking, and as reporting commonly depends on ground reporting systems which are subject to their own inherent limitations, sustaining monitoring systems is challenging (Elamein, Bower et al. 2017, Wong and Chen 2018). Notably, to date the population health impact of such attacks in Syria has not been well described or quantified.

The limited research on key health system pillars, namely governance, financing and essential medicines, is also of concern, particularly as governance and financing are critical to any consideration and planning for health system rebuilding. 
There is geographic variation in research volume and thematic issues examined.

Focus of research covering areas such as Damascus, a Syrian government stronghold, is heavily on population health status and the healthcare system, while research on northwest Syria (Aleppo and Idlib) focused more on the healthcare system, particularly attacks on healthcare and other IHL violations, and humanitarian needs and assistance. This likely reflects conflict events and response to evolving issues and operational needs on the ground, in addition to issues of access. International agencies and humanitarian organizations based in Turkey have access to the opposition-controlled areas of north/northwest Syria, directly or through Syrian/diasporic health and humanitarian organizations, including through cross-border assistance operations (UN Office for the Coordination of Humanitarian Affairs (UNOCHA) 2016, UN Office for the Coordination of Humanitarian Affairs (UNOCHA) 2017, United Nations High Commissioner for Refugees (UNHCR) 2019). This facilitates access to populations and humanitarian providers and collection of data. Surprisingly, research on northeast Syria is extremely limited. There is no research on non-government controlled areas controlled by IS, likely reflecting security and access issues.

Vulnerable groups and hard-to-reach populations receive limited research attention.

There is limited research on some specific population subgroups. The protracted conflict has resulted in a chronic and large-scale displacement inside Syria, with over 6 million IDPs today (Internal Displacement Monitoring Centre). New displacements are still occurring. It is estimated that 2.5 million Syrians were subjected to siege at some point during the conflict (Siege Watch 2019). As at April 2019, more than 144,000 Syrians had been imprisoned or disappeared (Syrian Network for Human Rights 2019). These highly vulnerable populations are rarely studied. For example, only three papers (Sahloul, Salem et al. 2017, Morrison 2018, Fardousi, Douedari et al. 2019), one field and operational activities publication (Masrani, Mamoun et al. 2018) and one personal narrative (Fakhouri 2017) covered issues of siege. Understanding the health status and humanitarian needs of such populations is essential in order to inform programmatic action.

Novel methodologies have been applied to study health in an active conflict zone.

Numerous challenges are reported in the conduct of this body of research, largely consistent with those described by researchers who have worked in and studied a range of other active conflict zones. These include issues of access, data quality, quantity and availability (including lack of denominator data due to ongoing population displacement), and security considerations, including impacts on participant willingness to engage. A number of novel tools and methodologies were developed and described in this literature in order to overcome research constraints and to study conflict-related health issues. Humanitarian interventions have been used to piggy-back health messaging and research. For instance, El-Khani et al distributed parenting psychosocial support information and questionnaires in humanitarian bread deliveries (El-Khani, Cartwright et al. 2016), highlighting the scope for existing humanitarian routes to both distribute information and serve as a research platform. Social media is increasingly used as a research tool, including in conflict settings. Research included in this review has used social media in a 
number of ways, including as a data collection tool (Alasaad 2013, Rosman, Eisenkraft et al. 2014, Elamein, Bower et al. 2017) and as a platform for delivery of an educational intervention (Alshiekhly, Arrar et al. 2015). Communication technologies have also been incorporated into research approaches, including through use of services such as WhatsApp as part of a tool to monitor attacks on healthcare in Syria (Elamein, Bower et al. 2017), and secure messaging platforms used for remote interviews and data collection, to overcome security considerations and access constraints (Footer, Clouse et al. 2018, Douedari and Howard 2019, Fardousi, Douedari et al. 2019).

Efforts to mitigate potential barriers to Syrian-led research in and on Syria warrant attention.

This review shows good representation of first/last authors from Syrian institutions, with approximately a third of first authors and a quarter of last authors having Syrian institutional affiliations. This does not reflect the total number of first and last authors from Syria or with Syrian background, as conflict-induced forced displacement of Syrian academics means that some are publishing but are now affiliated with Global North institutions.

There are several potential barriers to Syrian researcher engagement which warrant attention. These include general difficulties in access and insecurities, limited supply and/or capacity of Syrian researchers based inside Syria, and disruption or collapse of research infrastructure in Syrian institutions, including through recurrent attacks on universities, and widespread oppression of academics and freedom of speech more broadly which have had a detrimental impact on higher education institutions in Syria (Watenpaugh, Fricke et al. 2014, Bariscil 2017). Additionally, capacity building and training opportunities are limited: one study in this review reports lack of adequate training, research facilities and mentorship as barriers to research among undergraduates (Turk, Al Saadi et al. 2018) and others also describe additional resource and funding constraints (Saadi, Abbas et al. 2018).

Such barriers to local research production must be addressed. Utilization of various techniques, e.g. use of pseudonyms to address security concerns, and implementation of contextually appropriate capacity building initiatives and frameworks, such as that proposed by others (El Achi, Papamichail et al. 2019), to support more Syrian researchers and Syrian institutions to lead research on the health issues affecting their country and its people, is warranted.

Strengths and limitations

To the best of our knowledge, this is the first review to characterize the body of published peer-reviewed research examining health inside Syria over the course of the conflict. Themes assigned reflect the major focus of each paper and do not necessarily capture all issues covered. Relevant studies may have been excluded, or missed if published in journals not indexed in the seven health bibliographic databases searched. For example, Arabic language papers published in local or regional journals are not captured in this review. Furthermore, much operational research is published in non-peer reviewed platforms and organizational reports, so the findings of this review likely to do not fully capture all operational and field research undertaken by humanitarian organisations. 


\section{Conclusions}

Whilst there is a growing body of research examining population health issues inside conflict-ravaged Syria, there are considerable geographic and thematic gaps, and issues and populations that warrant focused research attention. Recognising the myriad of complexities of researching active conflict zones, including issues of data completeness, coverage and politicisation, it is essential that research in and on Syria continues, in order to build the evidence base and inform policy and programmatic actions that are required to protect and promote health in Syria following nearly a decade of conflict.

\section{Declarations}

\section{ETHICS APPROVAL AND CONSENT TO PARTICIPATE}

Not applicable as this is a literature review.

\section{CONSENT FOR PUBLICATION}

Not applicable as this is a literature review.

\section{AVAILABILITY OF DATA AND MATERIAL}

Research data and material are available for peer review.

\section{COMPETING INTERESTS}

No competing interests.

\section{FUNDING}

This study was funded by the Department for International Development (DFID)

\section{AUTHORS' CONTRIBUTIONS}

MA, SJ and MKE conceptualized the study. MKE and MA developed the study design. MKE developed and ran the search, screened results, abstracted and analysed data. MA abstracted data and wrote the first draft. MKE, MA and SJ reviewed all results. MA, MKE, IN and SJ edited the draft and approved the final manuscript for submission.

\section{ACKNOWLEDGEMENTS}

We thank Dr Omar Asfour for his useful comments on the development of this draft.

\section{References}


1. Abbas, F., B. Sawaf, I. Hanafi, M. Y. Hajeer, M. I. Zakaria, W. Abbas, F. Alabdeh and N. Ibrahim (2018). "Peers versus professional training of basic life support in Syria: a randomized controlled trial." BMC medical education18(1): 142.

2. Abdulahi, M. (2017). "Experiences of Nutrition Sector coordination in Syria." Field ExchangeEmergency Nutrition Network ENN(No.56): 25-28.

3. Abdullah, S. F. and L. S. Baker (2017). "Experiences of the 'Whole of Syria' coordination for nutrition." Field Exchange - Emergency Nutrition Network ENN(No.56): 79-83.

4. Abu Salem, F. K., R. Al Feel, S. Elbassuoni, M. Jaber and M. Farah (2019). "FA-KES: A fake news dataset around the Syrian War." Proceedings of the 13th International Conference on Web and Social Media, ICWSM 2019: 573-582.

5. Aburas, R., A. Najeeb, L. Baageel and T. K. Mackey (2018). "The Syrian conflict: A case study of the challenges and acute need for medical humanitarian operations for women and children internally displaced persons." BMC Medicine16(1): 65.

6. Ahmad, B. (2014). "Exploring the role of triangulation in the production of knowledge for urban health policy: an empirical study from informal settlements in Aleppo, Syria." Forum for Development Studies41(3): 433-454.

7. Ahmad, B., F. M. Fouad, S. Zaman and P. Phillimore (2018). "Women's health and well-being in lowincome formal and informal neighbourhoods on the eve of the armed conflict in Aleppo." International journal of public health64: 75-82.

8. Al-Makki, A., A. O. Rifai, L. Murad, A. R. Zanabli, A. Kayal, K. Soudan, M. Kherallah, F. Alsaghir and M. Sekkarie (2014). "The syrian national kidney foundation: Response for the need of kidney patients during the crisis." Avicenna journal of medicine4(3): 54-57.

9. Al-Saadi, T., S. Z. Addeen, T. Turk, F. Abbas and M. Alkhatib (2017). "Psychological distress among medical students in conflicts: a cross-sectional study from Syria." BMC Medical Education17(173).

10. Alahdab, F., M. H. Omar, S. Alsakka, A. Al-Moujahed and B. Atassi (2014). "Syrians' alternative to a health care system: "field hospitals"." Avicenna journal of medicine4(3): 51-53.

11. Alaryan, T., T. A. Hasan, M. Eshelli and S. Alzeer (2019). "The Misuse of Prescribed Drugs During the Syrian Crisis: a Cross-sectional Study." International Journal of Mental Health and Addiction.

12. Alasaad, S. (2013). "War diseases revealed by the social media: massive leishmaniasis outbreak in the Syrian Spring." Parasites Vectors6: 3.

13. Albaroudi, I. N., M. Khodder, T. Al Saadi, T. Turk and L. A. Youssef (2018). "Prevalence, diagnosis, and management of iron deficiency and iron deficiency anemia among Syrian children in a major outpatient center in Damascus, Syria." Avicenna journal of medicine8(3): 92-103.

14. Alhaffar, B. A., G. Abbas and A. A. Alhaffar (2019). "The prevalence of burnout syndrome among resident physicians in Syria." $\mathrm{J}$ Occup Med Toxicol14: 31.

15. Alhaffar, B. A., R. Alawabdi, L. Barakat and C. Kouchaji (2019). "Oral health and socio-economic status among children during Syrian crisis: a cross-sectional study." BMC Oral Health19(1): 165. 
16. Alhammoud, A., B. Maaz, G. A. Alhaneedi and M. Alnouri (2019). "External fixation for primary and definitive management of open long bone fractures: the Syrian war experience." Int Orthop $43(12)$ : 2661-2670.

17. Alothman, M. H., W. A. Tamer, L. R. Moscote-Salazar, A. Ghosh, R. Pal and A. Agrawal (2019). "Challenges and Opportunities in Reporting Trauma-Related Research: A Case Study from Syria." Indian Journal of Neurotrauma16(2-3): 91-93.

18. Alrifai, A., T. Alyousef and Z. Fanari (2018). "Tele-Cardiology in the Syrian War." J. Am. Coll. Cardiol.71(6): 698-699.

19. Alsaied, T., A. Mawas, F. Al Sayah, A. Kental and M. Saqqur (2017). "A new primary health-care system in the Syrian opposition territories: Good effort but far from being perfect." Avicenna journal of medicine7(4): 189-192.

20. Alshiekhly, U., R. Arrar, I. Barngkgei and M. Dashash (2015). "Facebook as a learning environment for teaching medical emergencies in dental practice." Education for health (Abingdon, England).28(3): 176-180.

21. Arafat, S., M. B. Alsabek, M. Ahmad, I. Hamo and E. Munder (2017). "Penetrating abdominal injuries during the Syrian war: Patterns and factors affecting mortality rates." Injury.48(5): 1054-1057.

22. Attar, S. (2014). "Field hospitals in Syria." Lancet (London, England)383(9914): 303.

23. Attar, S. (2014). "Syria's humanitarian crisis." Journal of Bone and Joint Surgery-American Volume96(9): e74.71-e74.73.

24. Attar, S. (2016). "The Hell of Syria's Field Hospitals." New England Journal of Medicine374(23): 22052207.

25. Baaity, Z., I. Almahmoud and A. Khamis (2017). "Prevalence of extended spectrum $\beta$ lactamases (ESBL) in E. coli at Al-assad teaching hospital." Research Journal of Pharmacy and Technology_10(7): 2433-2436.

26. Ballouk, M. A. and M. Dashash (2018). "The gingival health status of 8-12 year-old children in Damascus city in Syria during the Syrian Crisis: a cross-sectional epidemiological oral health survey." BMC research notes 11(1): 887.

27. Ballouk, M. A. and M. Dashash (2019). "Caries prevalence and dental health of 8-12 year-old children in Damascus city in Syria during the Syrian Crisis; a cross-sectional epidemiological oral health survey." BMC Oral Health19(1): 16.

28. Bariscil, A. (2017). "An Emergency Academic Support - Syrian Refugee Students in the Turkish Higher Education." Romanian Journal for Multidimensional Education / Revista Romaneasca pentru Educatie Multidimensionala9(1): 39-49.

29. Blackwell, A., J. Casey, R. Habeeb, J. Annan and K. Falb (2019). "Women's status and qualitative perceptions of a cash assistance programme in Raqqa Governorate, Syria." Gender and Development27(2): 253-271.

30. Charlson, F. J., Y. Y. Lee, S. Diminic and H. Whiteford (2016). "Applications of the epidemiological modelling outputs for targeted mental health planning in conflict-affected populations: the Syria 
case-study." Global mental health3: e8.

31. Chen, B., A. Shrivastava and R. C. Steorts (2018). "UNIQUE ENTITY ESTIMATION WITH APPLICATION TO THE SYRIAN CONFLICT." Ann. Appl. Stat.12(2): 1039-1067.

32. Coutts, A., F. M. Fouad, A. Abbara, A. M. Sibai, Z. Sahloul and K. Blanchet (2015). "Responding to the Syrian health crisis: the need for data and research." The Lancet. Respiratory medicine3(3): e8-9.

33. Cummins, D. and S. Moharram (2017). "Aid in context: the importance of market-based approaches to aid delivery in northern Syria." IIED Briefing Paper - International Institute for Environment and Development(No.17424): 4 pp.

34. Darwish, B., M. Z. Mahfouz, S. Al-Nosairat and M. B. Izzat (2018). "Changing pattern and outcome of pediatric chest injuries in urban Syria." Asian cardiovascular \& thoracic annals26(5): 367-370.

35. de Lima Pereira, A., R. Southgate, H. Ahmed, P. O'Connor, V. Cramond and A. Lenglet (2018). "Infectious Disease Risk and Vaccination in Northern Syria after 5 Years of Civil War: The MSF Experience." PLoS currents10.

36. Diggle, E., W. Welsch, R. Sullivan, G. Alkema, A. Warsame, M. Wafai, M. Jasem, A. Ekzayez, R. Cummings and P. Patel (2017). "The role of public health information in assistance to populations living in opposition and contested areas of Syria, 2012-2014." Conflict and health11: 33.

37. Dolan, C. (2014). "Coordinating the response to the Syria crisis: the southern Turkey cross border experience." Field Exchange - Emergency Nutrition Network ENN(No.48): 138-139.

38. Doocy, S., T. D. Delbiso and D. Guha-Sapir (2015). "The humanitarian situation in syria: a snapshot in the third year of the crisis." PLoS currents7.

39. Doocy, S. and E. Lyles (2017). "Humanitarian Needs Among Displaced and Female-Headed Households in Government-Controlled Areas of Syria." American journal of public health107(6): 950959.

40. Doocy, S. and E. Lyles (2018). "Humanitarian Needs in Government Controlled Areas of Syria." PLoS currents 10.

41. Doocy, S., E. Lyles, T. D. Delbiso and C. W. Robinson (2015). "Internal displacement and the Syrian crisis: an analysis of trends from 2011-2014." Conflict and health9: 33.

42. Doocy, S., H. Tappis, E. Lyles, J. Witiw and V. Aken (2017). "Emergency Food Assistance in Northern Syria: An Evaluation of Transfer Programs in Idleb Governorate." Food and nutrition bulletin38(2): 240-259.

43. Douedari, Y. and N. Howard (2019). "Perspectives on Rebuilding Health System Governance in Opposition-Controlled Syria: A Qualitative Study." Int J Health Policy_Manag8(4): 233-244.

44. Duclos, D., A. Ekzayez, F. Ghaddar, F. Checchi and K. Blanchet (2019). "Localisation and cross-border assistance to deliver humanitarian health services in North-West Syria: a qualitative inquiry for The Lancet-AUB Commission on Syria." Confl Health13: 20.

45. Egendal, R. and A. Badejo (2014). "WFP's emergency programme in Syria." Field Exchange Emergency Nutrition Network ENN(No.48): 113-117. 
46. El-Khani, A., K. Cartwright, A. Redmond and R. Calam (2016). "Daily bread: a novel vehicle for dissemination and evaluation of psychological first aid for families exposed to armed conflict in Syria." Global mental health (Cambridge, England)3: e15.

47. El-Khatib, Z., D. Scales, J. Vearey and B. C. Forsberg (2013). "Syrian refugees, between rocky crisis in Syria and hard inaccessibility to healthcare services in Lebanon and Jordan." Confl Health7(1): 18.

48. El Achi, N., A. Papamichail, A. Rizk, H. Lindsay, M. Menassa, R. Abdul-Khalek, A. Ekzayez, O. Dewachi and P. Patel (2019). "A conceptual framework for capacity strengthening of health research in conflict: the case of the Middle East and North Africa region." Globalization and Health15(81).

49. El Arnaout, N., S. Rutherford, T. Zreik, D. Nabulsi, N. Yassin and S. Saleh (2019). "Assessment of the health needs of Syrian refugees in Lebanon and Syria's neighboring countries." $\underline{\text { Conflict and }}$ health13(1): 31.

50. Elamein, M., H. Bower, C. Valderrama, Z. Daher, H. Rihawi, K. Almilaji, M. Abdelhafeez, N. Tabbal, N. Almhawish, S. Maes and A. AbouZeid (2017). "Attacks against health care in Syria, 2015-16: results from a real-time reporting tool." The Lancet390(10109): 2278-2286.

51. Elamein, M., H. Bower, C. Valderrama, D. Zedan, H. Rihawi, K. Almilaji, M. Abdelhafeez, N. Tabbal, N. Almhawish, S. Maes and A. AbouZeid (2017). "Attacks against health care in Syria, 2015-16: results from a real-time reporting tool." The Lancet390(10109): 2278-2286.

52. Elsafti, A. M., G. van Berlaer, M. Al Safadi, M. Debacker, R. Buyl, A. Redwan and I. Hubloue (2016). "Children in the Syrian Civil War: the Familial, Educational, and Public Health Impact of Ongoing Violence." Disaster medicine and public health preparedness 10(6): 874-882.

53. Fakhouri, F. (2017). "Neurosurgery under siege - Stories from Aleppo and the Syrian war: A narrative article." Asian journal of neurosurgery.12(2): 342-343.

54. Falb, K. L., A. Blackwell, J. Stennes, M. Hussein and J. Annan (2019). "Depressive symptoms among women in Raqqa Governorate, Syria: associations with intimate partner violence, food insecurity, and perceived needs." Glob Ment Health (amb) 6: e22.

55. Fardousi, N., Y. Douedari and N. Howard (2019). "Healthcare under siege: a qualitative study of health-worker responses to targeting and besiegement in Syria." BMJ Open 9(9): e029651.

56. Footer, K. H. A., E. Clouse, D. Rayes, Z. Sahloul and L. S. Rubenstein (2018). "Qualitative accounts from Syrian health professionals regarding violations of the right to health, including the use of chemical weapons, in opposition-held Syria." BMJ open8(8): e021096.

57. Fouad, F. M., A. Sparrow, A. Tarakji, M. Alameddine, F. El-Jardali, A. P. Coutts, N. El Arnaout, L. B. Karroum, M. Jawad and S. Roborgh (2017). "Health workers and the weaponisation of health care in Syria: a preliminary inquiry for The Lancet-American University of Beirut Commission on Syria." The Lancet390(10111): 2516-2526.

58. Fradejas-Garcia, I. (2019). "Humanitarian remoteness: aid work practices from 'little Aleppo'." Social Anthropology27(2): 286-303.

59. Fujita, K., S. Shinomoto and L. E. C. Rocha (2017). "Correlations and forecast of death tolls in the Syrian conflict." Scientific reports7(1): 15737. 
60. Garry, S., F. Checchi and B. Cislaghi (2018). "What influenced provision of non-communicable disease healthcare in the Syrian conflict, from policy to implementation? A qualitative study." Conflict and health 12: 45.

61. Ghbeis, M. B., K. M. Steffen, E. A. Braunlin, G. J. Beilman, J. Dahman, W. Ostwani and M. E. Steiner (2018). "Tele-Pediatric Intensive Care for Critically III Children in Syria." Telemedicine journal and ehealth : the official journal of the American Telemedicine Association24(8): 621-623.

62. Guha-Sapir, D., J. M. Rodriguez-Llanes, M. H. Hicks, A. F. Donneau, A. Coutts, L. Lillywhite and F. M. Fouad (2015). "Civilian deaths from weapons used in the Syrian conflict." BMJ (Clinical research ed.).351: h4736.

63. Guha-Sapir, D., B. Schlüter, J. M. Rodriguez-Llanes, L. Lillywhite and M. H. R. Hicks (2018). "Patterns of civilian and child deaths due to war-related violence in Syria: a comparative analysis from the Violation Documentation Center dataset, 2011-16." The Lancet Global Health6(1): e103-e110.

64. Haar, R. J., C. B. Risko, S. Singh, D. Rayes, A. Albaik, M. Alnajar, M. Kewara, E. Clouse, E. Baker and L. S. Rubenstein (2018). "Determining the scope of attacks on health in four governorates of Syria in 2016: Results of a field surveillance program." PLoS medicine15(4): e1002559.

65. Hakeem, O. and S. Jabri (2015). "Adverse birth outcomes in women exposed to Syrian chemical attack." The Lancet. Global health3(4): e196.

66. Hallak, J., M. Koyuncu and P. Mic (2019). "Determining shelter locations in conflict areas by multiobjective modeling: A case study in northern Syria." International Journal of Disaster Risk Reduction38: 15.

67. Hallam, R. (2013). "Response to Syria's health crisis." The Lancet382(9893): 679-680.

68. Hamid, S. H. and M. A. D. Dashash (2018). "The impact of post-traumatic stress disorder on dental and gingival status of children during syrian crisis: A preliminary study." Journal of investigative and clinical dentistry: e12372.

69. Hamzeh, A., G. Almhanni, Y. Aljaber, R. Alhasan, R. Alhasan, M. I. Alsamman, N. Alhalabi and Y. Haddeh (2019). "Awareness of diabetes and diabetic retinopathy among a group of diabetic patients in main public hospitals in Damascus, Syria during the Syrian crisis." BMC Health Serv Res 19(1): 549.

70. Harrison, S., R. Dahman, M. Ismail, E. Saada, M. Hassan, R. Hassan, A. Musa Khalifa and M. Schilperoord (2013). "'Against all odds': UNHCR's mental health and psychosocial support programme for Iraqi refugees and internally displaced Syrians." Intervention11(2): 190-194.

71. Hasanin, A., A. Mukhtar, A. Mokhtar and A. Radwan (2013). "Syrian revolution: a field hospital under attack." American journal of disaster medicine8(4): 259-265.

72. Hawat, M., M. Husein and I. Almahmoud (2017). "Epidemiology of leishmaniasis in Lattakia city among last ten years (2006-2016)." Epidemiology: Open Access7(5): 325.

73. Hoetjes, M., W. Rhymer, L. Matasci-Phelippeau and S. v. d. Kam (2014). "Emerging cases of malnutrition amongst IDPs in Tal Abyad district, Syria." Field Exchange - Emergency Nutrition Network ENN(No.48): 133-137. 
74. Idris, A., T. Al Saadi, T. Turk, M. Alkhatib, M. Zakaria, B. Sawaf and B. Edris (2018). "Smoking behaviour and patterns among university students during the Syrian crisis." Eastern Mediterranean $\underline{\text { health }}$ journal $=$ La revue de sante de la Mediterranee orientale $=$ al-Majallah al-sihhiyah li-sharg almutawassit24(2): 154-160.

75. Internal Displacement Monitoring Centre. "The global report on internal displacement 2019." Retrieved Oct, 2019, from http://www.internal-displacement.org/global-report/grid2019/

76. Ismail, S. A., A. Abbara, S. M. Collin, M. Orcutt, A. P. Coutts, W. Maziak, Z. Sahloul, O. Dar, T. Corrah and F. M. Fouad (2016). "Communicable disease surveillance and control in the context of conflict and mass displacement in Syria." International journal of infectious diseases : IJID : official publication of the International Society for Infectious Diseases47: 15-22.

77. Jamal, Z., M. Alameddine, K. Diaconu, G. Lough, S. Witter, A. Ager and F. M. Fouad (2019). "Health system resilience in the face of crisis: analysing the challenges, strategies and capacities for UNRWA in Syria." Health Policy Plan.

78. Jefee-Bahloul, H., A. Barkil-Oteo, N. Shukair, W. Alraas and W. Mahasneh (2016). "Using a Store-andForward System to Provide Global Telemental Health Supervision and Training: A Case from Syria." Academic psychiatry: the journal of the American Association of Directors of Psychiatric Residency. Training and the Association for Academic Psychiatry40(4): 707-709.

79. Jefee-Bahloul, H., D. Duchen and A. Barkil-Oteo (2016). "Attitudes Towards Implementation of Storeand-Forward Telemental Health in Humanitarian Settings: Survey of Syrian Healthcare Providers." Telemedicine journal and e-health : the official journal of the American Telemedicine Association22(1): 31-35.

80. Joury, E. (2014). "Constructing hope and peace in Syrian dental education during the country's time of difficulty: Success in Syrian smiles." Education for Health27(1): 71-72.

81. Kaadan, M. I. and H. Cranmer (2018). "The Management of the Khan Al-Assal Chemical Attack in Aleppo University Hospital (AUH)." Disaster medicine and public health preparedness 12(5): 663-665.

82. Kassem, M. (2016). "A Syrian neurosurgeon's journey." Surgical neurology international7: 6.

83. Khamis, J. and A. Ghaddar (2018). "HIV/AIDS in Syria and the response of the National AIDS Program during the war." Sexually transmitted infections 94(3): 173.

84. Khudari, H., M. Bozo and E. Hoff (2014). "WHO response to malnutrition in Syria: a focus on surveillance, case detection and clinical management." Field Exchange - Emergency Nutrition Network ENN(No.48): 118-121.

85. Kingori, J., H. Nasser, M. Abdullahi and K. Al-Asaad (2014). "Nutrition response to the Syria crisis: UNICEF's perspective." Field Exchange - Emergency Nutrition Network ENN(No.48): 160-163.

86. Kouba, L., B. Amin and A. Azzam (2019). "Online education opportunity for Syria's future doctors." Lancet394(10211): 1805-1806.

87. Kubitary, A. and M. A. Alsaleh (2018). "Validity of Arabic version of the two-question Quick Inventory of Depression (QID-2-Ar): Screening for multiple sclerosis in an Arab environment and during the Syrian war." Revue neurologique174(3): 137-144. 
88. Kubitary, A. and M. A. Alsaleh (2018). "War Experiences, Posttraumatic Stress Disorder, Sleep Disorders: Clinical Effectiveness of Treatment by Repeating Phrases of Positive Thoughts (TRPPT) of Mental-War Disorders in Syrian Refugees Children and Adolescents War Victims - A New Therapeutic Trial." Sleep \& Hypnosis 20(3): 210-226.

89. Lester, N. (2018). "Introducing a trauma-informed practice framework to provide support in conflictaffected countries: The case of the Syrian white helmets." RUSI Journal163(6): 28-41.

90. Littledike, E. and C. Beck (2014). "Experiences and challenges of programming in Northern Syria." Field Exchange - Emergency Nutrition Network ENN(No.48): 122-125.

91. Madani, W. B. M. (2017). "Development and added value of the Nutrition Cluster in Turkey." Field Exchange - Emergency Nutrition Network ENN(No.56): 11-15.

92. Mahomed, Z., F. Motara and A. Bham (2016). "Humanitarian Medical Response to the Syrian Arab Republic (April 7, 2013 to April 23, 2013)." Prehospital and disaster medicine31(1): 114-116.

93. Masrani, A., I. Mamoun, B. Tarabishy, A. Tarabishy and M. Arabi (2018). "Delivering Humanitarian Teleradiology Services to Besieged Areas in Syria." Journal of the American College of Radiology: JACR15(8): 1175-1177.

94. Mbaeyi, C., Z. M. Wadood, T. Moran, F. Ather, T. Stehling-Ariza, J. Nikulin, M. Al Safadi, J. Iber, L. Zomahoun, N. Abourshaid, P. Hong, N. Collins, H. Asghar, O. u. I. Butt, C. C. Burns, D. Ehrhardt and M. Sharaf (2018). "Strategic response to an outbreak of circulating vaccine-derived poliovirus type 2, Syrian Arab Republic, 2017-2018." Weekly_Epidemiological Record93(25): 362-368.

95. Meiqari, L., M. Hoetjes, L. Baxter and A. Lenglet (2018). "Impact of war on child health in northern Syria: the experience of Medecins Sans Frontieres." Eur. J. Pediatr.177(3): 371-380.

96. Mic, P., M. Koyuncu and J. Hallak (2019). "Primary Health Care Center (PHCC) Location-Allocation with Multi-Objective Modelling: A Case Study in Idleb, Syria." Int J Environ Res Public Health16(5).

97. Mipatrini, D., P. Stefanelli, S. Severoni and G. Rezza (2017). "Vaccinations in migrants and refugees: a challenge for European health systems. A systematic review of current scientific evidence." Pathogens and global health111(2): 59-68.

98. Mohammad, A., I. Mamoun, A. Masrani, M. Alsayid and N. Haroun (2017). "Practice of teleradiology in crisis zones: the unique case of Syria." Lancet Global Health5(4): e399-e400.

99. Mohammad, Y., S. Rafea, Y. Latifeh, A. Khaddam, B. Sawaf, M. I. Zakaria, M. S. Al Masalmeh, Y. Fawaz, A. Allaham, I. Almani, H. El-Tarcheh, A. Ghazal, A. Zaher, H. Rifai, H. Joumah, S. D. GlocklerLauf and T. To (2017). "Uncontrolled and under-diagnosed asthma in a Damascus shelter during the Syrian crisis." Journal of thoracic disease9(9): 3415-3424.

100. Mohammad, Y., R. Shaaban, H. A. Salman, B. N. Shabraq and B. Dubaybo (2019). "Improving the quality of hospital care provided for asthma out-patients in a country in turmoil: a report from Syria." J Thorac Dis11(3): 1047-1055.

101. Morrison, C. (2018). "Providing basic services under siege: preliminary insights from interim councils and medical providers in besieged urban areas of Syria." Environment and Urbanization31(1): 309324. 
102. Moughrabieh, A. and C. Weinert (2016). "Rapid Deployment of International Tele-Intensive Care Unit Services in War-Torn Syria." Annals of the American Thoracic Society.13(2): 165-172.

103. Mowafi, H., M. Hariri, H. Alnahhas, E. Ludwig, T. Allodami, B. Mahameed, J. K. Koly, A. Aldbis, M. Saqqur, B. Zhang and A. Al-Kassem (2016). "Results of a Nationwide Capacity Survey of Hospitals Providing Trauma Care in War-Affected Syria." JAMA surgery151(9): 815-822.

104. Muhjazi, G., S. Baghdadi, C. Dye and M. Qusaibaty (2018). "Sustaining a national tuberculosis control programme during civil crisis: 6 years of experience in Syria." The Lancet. Respiratory. medicine6(4): 255-256.

105. Muhjazi, G., A. F. Gabrielli, J. A. Ruiz-Postigo, H. Atta, M. Osman, H. Bashour, A. Al Tawil, H. Husseiny, R. Allahham and R. Allan (2019). "Cutaneous leishmaniasis in Syria: A review of available data during the war years: 2011-2018." PLoS Negl Trop Dis13(12): e0007827.

106. Okeeffe, J., L. Vernier, V. Cramond, S. Majeed, A. I. C. Martin, M. Hoetjes and M. Amirtharajah (2019). "The blast wounded of Raqqa, Syria: observational results from an MSF-supported district hospital." Conflict and Health13: 9.

107. Othman, M., Z. Steel, C. Lawsin and R. Wells (2018). "Addressing occupational stress among health staff in nongovernment controlled Northern Syria: Supporting resilience in a dangerous workplace." Torture28(3): 104-123.

108. Perkins, J. D., M. Ajeeb, L. Fadel and G. Saleh (2018). "Mental health in Syrian children with a focus on post-traumatic stress: a cross-sectional study from Syrian schools." Social psychiatry and psychiatric epidemiology53(11): 1231-1239.

109. Price, M., A. Gohdes and P. Ball (2015). "Documents of war: Understanding the Syrian conflict." Significance12(2): 14-19.

110. Quay, I. (2019). "Rapid Gender Analysis and its use in crises: from zero to fifty in five years." Gender and Development27(2): 221-236.

111. Reed, H. (2014). "GOAL's food and voucher assistance programme in Northern Syria." Field Exchange - Emergency Nutrition Network ENN(No.48): 128-132.

112. Rehman, K., J. Walochnik, J. Mischlinger, B. Alassil, R. Allan and M. Ramharter (2018). "Leishmaniasis in Northern Syria during Civil War." Emerging infectious diseases24(11): 1973-1981.

113. Rehr, M., M. Shoaib, S. Ellithy, S. Okour, C. Ariti, I. Ait-Bouziad, P. van den Bosch, A. Deprade, M. Altarawneh, A. Shafei, S. Gabashneh and A. Lenglet (2018). "Prevalence of non-communicable diseases and access to care among non-camp Syrian refugees in northern Jordan." Conflict and health12(33).

114. Ri, S., A. H. Blair, C. J. Kim and R. J. Haar (2019). "Attacks on healthcare facilities as an indicator of violence against civilians in Syria: An exploratory analysis of open-source data." PLoS One14(6): e0217905.

115. Rodriguez-Llanes, J. M., D. Guha-Sapir, B. S. Schluter and M. H. Hicks (2018). "Epidemiological findings of major chemical attacks in the Syrian war are consistent with civilian targeting: a short report." Conflict and health12: 16. 
116. Rosman, Y., A. Eisenkraft, N. Milk, A. Shiyovich, N. Ophir, S. Shrot, Y. Kreiss and M. Kassirer (2014). "Lessons learned from the Syrian sarin attack: evaluation of a clinical syndrome through social media." Annals of internal medicine160(9): 644-648.

117. Roumieh, M., H. Bashour, M. Kharouf and S. Chaikha (2019). "Prevalence and risk factors for postpartum depression among women seen at Primary Health Care Centres in Damascus." BMC Pregnancy Childbirth19(1): 519.

118. Saadi, T. A., F. Abbas, T. Turk, M. Alkhatib, I. Hanafi and F. Alahdab (2018). "Medical research in wartorn Syria: medical students' perspective." The Lancet391(10139): 2497-2498.

119. Saeed, B. (2015). "The effect of the Syrian crisis on organ transplantation in Syria." Experimental and clinical transplantation : official journal of the Middle East Society for Organ Transplantation13(2): 206-208.

120. Sahloul, E., R. Salem, W. Alrez, T. Alkarim, A. Sukari, W. Maziak and M. B. Atassi (2017). "Cancer Care at Times of Crisis and War: The Syrian Example." Journal of global oncology3(4): 338-345.

121. Sankari, A., B. Atassi and M. Z. Sahloul (2013). "Syrian field hospitals: A creative solution in urban military conflict combat in Syria." Avicenna journal of medicine3(3): 84-86.

122. Sawaf, B., F. Abbas, A. Idris, T. Al Saadi and N. Ibrahim (2018). "Specialty preference and intentions to study abroad of Syrian medical students during the crisis." BMC medical education 18(1): 39.

123. Sekkarie, M. A., A. R. Zanabli, A. O. Rifai, L. B. Murad and A. A. Al-Makki (2015). "The Syrian conflict: assessment of the ESRD system and response to hemodialysis needs during a humanitarian and medical crisis." Kidney international87(2): 262-265.

124. Siege Watch. (2019). "Siege Watch: Final Report - Out of Sight, Out of Mind: The Aftermath of Syria's Sieges." Retrieved Oct, 2019, from https://siegewatch.org/wp-content/uploads/2015/10/pax-siegewatch-final-report-spread.pdf.

125. Sigal, I. (2016). Syria's war may be the most documented ever. And yet, we know so little The World.

126. Sikder, M., U. Daraz, D. Lantagne and R. Saltori (2018). "Water, sanitation, and hygiene access in southern Syria: analysis of survey data and recommendations for response." Conflict and health $\mathbf{1 2}$ : 17.

127. Sparrow, A., K. Almilaji, B. Tajaldin, N. Teodoro and P. Langton (2016). "Cholera in the time of war: implications of weak surveillance in Syria for the WHO's preparedness-a comparison of two monitoring systems." BMJ global health1(3): e000029.

128. Syrian Network for Human Rights. (2019). "Record of Arbitrary Arrests." Retrieved Oct, 2019, from http://sn4hr.org/blog/2018/09/24/record-of-arbitrary-arrests1/.

129. Tajaldin, B., K. Almilaji, P. Langton and A. Sparrow (2015). "Defining Polio: Closing the Gap in Global Surveillance." Annals of global health81(3): 386-395.

130. Taleb, Z. B., R. Bahelah, F. M. Fouad, A. Coutts, M. Wilcox and W. Maziak (2015). "Syria: health in a country undergoing tragic transition." International journal of public health60: S63-72. 
131. Terkawi, A. S., B. Bakri, A. S. Alsadek, A. H. Al-Hasan, M. S. Alrahhal, F. M. Alsaleh, F. A. Alsatouf, M. A. I. Arab, H. Jnaid, A. A. Hadid, R. S. Terkawi, M. M. Zahran, N. A. Alghannam and K. A. Altirkawi (2019). "Child and adolescent health in northwestern Syria: findings from Healthy-Syria 2017 study." Avicenna J Med9(2): 61-74.

132. Terkawi, A. S., B. Bakri, A. S. Alsadek, R. H. Alsibaee, E. M. Alasfar, A. H. Albakour, A. Y. Aljouja, N. A. Alshaikhwais, F. A. Fares, P. D. Flood, H. Jnaid, A. A. Najib, D. A. Saloom, N. A. Zahra and K. A. Altirkawi (2019). "Women's health in Northwestern Syria: Findings from Healthy-Syria 2017 study." Avicenna J Med9(3): 94-106.

133. Trelles, M., L. Dominguez, K. Tayler-Smith, K. Kisswani, A. Zerboni, T. Vandenborre, S. Dallatomasina, A. Rahmoun and M. C. Ferir (2015). "Providing surgery in a war-torn context: the Medecins Sans Frontieres experience in Syria." Conflict and health9: 36.

134. Turk, T., O. A. Aboshady and A. Albittar (2016). "Studying medicine in crisis: Students' perspectives from Syria." Medical teacher38(8): 861-862.

135. Turk, T., T. Al Saadi, M. Alkhatib, I. Hanafi, F. Alahdab, B. Firwana, M. Koudsi and A. Al-Moujahed (2018). "Attitudes, barriers, and practices toward research and publication among medical students at the University of Damascus, Syria." Avicenna journal of medicine8(1): 24-33.

136. UN Office for the Coordination of Humanitarian Affairs (UNOCHA). (2016). "Overview: 2016 Syria Humanitarian Response Plan \& 2016 - 2017 Regional Refugee and Resilience Plan." from https://reliefweb.int/report/syrian-arab-republic/overview-2016-syria-humanitarian-response-plan2016-2017-regional.

137. UN Office for the Coordination of Humanitarian Affairs (UNOCHA) (2017). Turkey/Syria: Operational Presence of Syrian Civil Society Organizations - Overview, October 2017.

138. United Nations High Commissioner for Refugees (UNHCR). (2019). "Syria Regional Refugee Response." Retrieved September, 2019, from https://data2.unhcr.org/en/situations/syria.

139. van Berlaer, G., A. M. Elsafti, M. Al Safadi, S. Souhil Saeed, R. Buyl, M. Debacker, A. Redwan and I. Hubloue (2017). "Diagnoses, infections and injuries in Northern Syrian children during the civil war: A cross-sectional study." PloS one12(9): e0182770.

140. Vernier, L., V. Cramond, M. Hoetjes, A. Lenglet, T. Hoare, R. Malaeb and A. I. Carrion Martin (2019). "High levels of mortality, exposure to violence and psychological distress experienced by the internally displaced population of Ein Issa camp prior to and during their displacement in Northeast Syria, November 2017." Confl Health13: 33.

141. Watenpaugh, K., A. Fricke, J. King, C. Gratien and S. Yilmaz (2014). We will stop here and go no further: Syrian university students and scholars in Turkey. [New York], Institute of International Education: $55 \mathrm{p}$.

142. Wong, C. H. and C. Y. Chen (2018). "Ambulances under siege in Syria." BMJ global health3(6): e001003.

143. World Health Organization. (2007). "Everybody's business. Strengthening health systems to improve health outcomes: WHO's framework for action." from 
https://www.who.int/healthsystems/strategy/everybodys_business.pdf.

144. Youssef, A., R. Harfouch, S. El Zein, Z. Alshehabi, R. Shaaban and S. S. Kanj (2019). "Visceral and Cutaneous Leishmaniases in a City in Syria and the Effects of the Syrian Conflict." Am J Trop Med Hyg.g101(1): 108-112.

145. Ziveri, D., S. Kiani and M. Broquet (2019). "The impact of psychosocial support on well-being and agency within an inclusive livelihood programme." Intervention (15718883)17(1): 86-95.

\section{Table}

Due to technical limitations, tables docx is only available as a download in the Supplemental Files section.

\section{Figures}

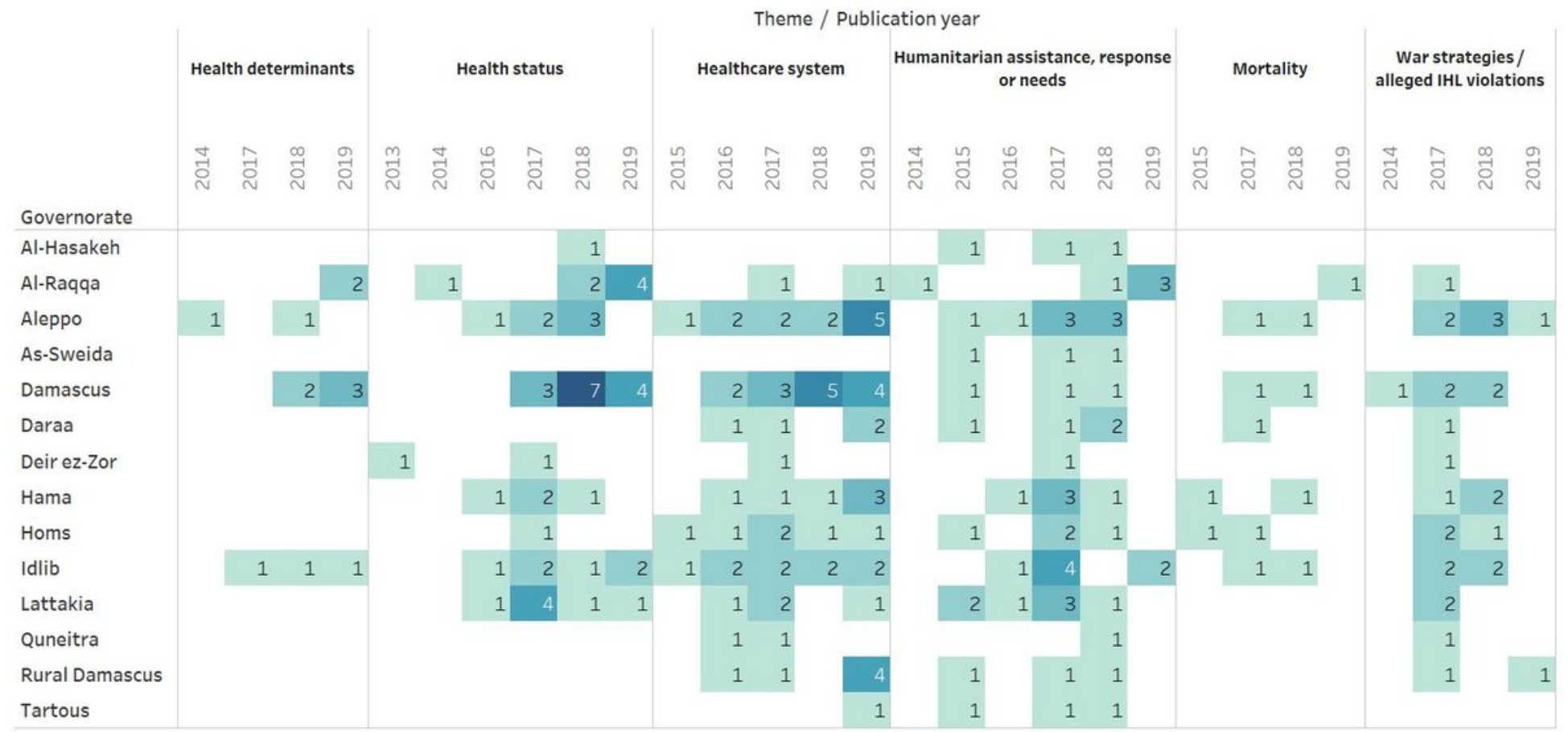

\section{Figure 1}

Governorates examined in research publications on health inside Syria by themes, January 2011December 2019

\section{Supplementary Files}

This is a list of supplementary files associated with this preprint. Click to download.

- AbouzeidElzalabanyCRRSyriaTablessubmitted.docx 